\title{
Campylobacter jejuni and thrombotic thrombocytopenic purpura
}

\author{
ROMAN JAESCHKE, MD, E JAN IRVINE, MD, JANE MOORE, ART, JOHN KELTON, MD
}

\begin{abstract}
Gastrointestinal bacterial infections could be associated with multisystem complication due to the thrombotic phenomena. This paper reports the association of Campylobacter jejuni infection and thrombotic thrombocytopenic purpura, and describes a new test for diagnosing thrombocytopenic purpura. Can J Gastroenterol 1990;4(4):154-156
\end{abstract}

Key Words: Campylobacter jejuni, Hemolytic uremic syndrome, Thrombotic thrombocytopenic purpura

\section{Campylobacter jejuni et le purpura thrombotique thrombocytopénique}

RESUME: Les infections gastro-intestinales d'origine bactérienne pourraient être associées à une complication agissant sur de multiples organes et due aux phénomènes thrombotiques. Cet article rapporte l'association existant entre l'infection à Campylobacter jejuni et le purpura thrombotique thrombocytopénique (PTT), et décrit un test nouveau permettant de diagnostiquer le PTT.

Departments of Medicine, Clinical Epidemiology and Biostatistics, and Pathology, McMaster University, Hamilton, Ontario; and Department of Medicine, St Joseph's Hospital, Hamilton, Ontario

Correspondence and reprints: Dr R Jaeschke, St Joseph's Hospital, Fontbonne Bldg,

Hamilton, Ontario L8N 4A6. Telephone (416) 525-9140 ext 2160

Received for publication February 6, 1990. Accepted March 23, 1990
$\mathrm{T}$ AROMBOCYTOPENIA AND SCHISTOcytic hemolytic anemia charac terize a group of disorders that are uncommon but important because of their potentially serious outcomes. Two of these disorders, thrombotic thrombocytopenic purpura and hemolytic uremic syndrome, share a number of similarities while exhibiting some unique features (1). Hemolytic uremic syndrome is characterized by thrombocytopenia, schistocytic hemolytic anemia, and renal failure. Recent studies have shown that many episodes of hemolytic uremic syndrome follow infection, often with a verotoxinproducing Escherichia coli (2). Other infectious gastrointestinal organisms, including campylobacter, shigella and salmonella, can cause hemolytic uremic syndrome as well. Thrombotic thrombocytopenic purpura, like hemolytic uremic syndrome, is characterized by thrombocytopenia and schis- 


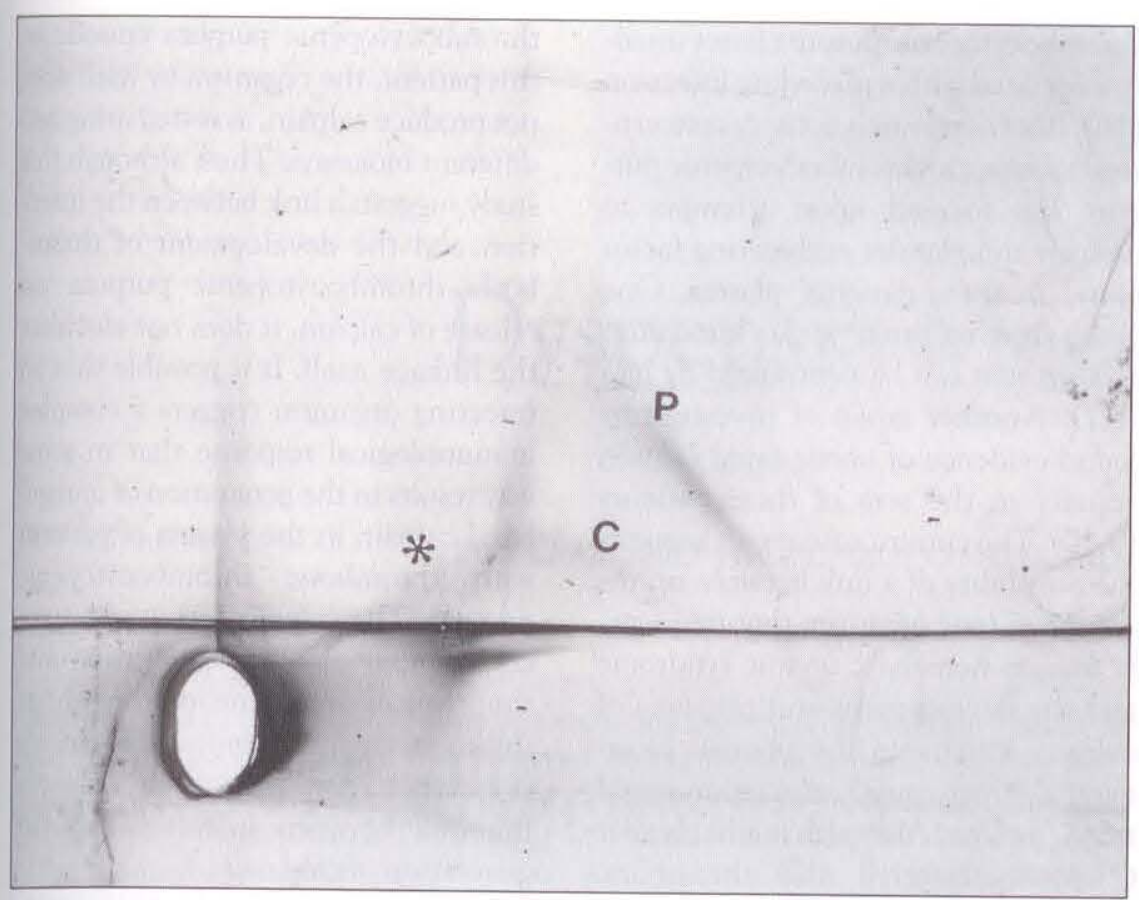

Figure 1) The pattern of von Willebrand factor obtained with the use of crossed immunoelectrophoresis. In comparison with control (C), the patient's serum (P) demonstrates lack of the large multimers $\left(^{*}\right)$ and an increased total level of the factor

tocytic hemolytic anemia, but neurological lesions are more frequent than renal impairment. Recent studies in thrombotic thrombocytopenic purpura have focused upon the characterization of a platelet aggregating factor in the serum of these patients (3-10). This factor could be of pathogenetic importance if it proved to induce in vivo platelet aggregation.

In this report the authors describe the investigation of a patient who had a thrombotic thrombocytopenic purpura preceded by an infection which has more typically been associated with hemolytic uremic syndrome. The patient had a platelet aggregating factor present in her serum that has been described to occur in patients with spontaneously occurring thrombotic thrombocytopenic purpura.

\section{CASE PRESENTATION}

A 73-year-old woman had a three day history of abdominal discomfort with cramps, vomiting and diarrhea. She was admitted to hospital and stool cultures grew Campylobacter jejuni. Treatment with erythromycin produced a partial resolution of her symptoms. However, over the next several days she had a progressive fall in both platelet count (to $18 \times 10^{9} / \mathrm{L}$ ) and hemoglobin level (to $105 \mathrm{~g} / \mathrm{L}$ ). Extensive red cell fragmentation was observed on a peripheral blood film. Coagulation tests were normal and showed no evidence of disseminated intravascular coagulation. Blood cultures were negative. Renal function was normal and a presumptive diagnosis of thrombotic thrombocytopenic purpura was made. The patient was initially treated with plasma infusion (100 $\mathrm{mL} / \mathrm{h}$ ), but because of a failure to respond she was treated with plasmapheresis. A total of seven apheresis procedures of two to three plasma exchanges each, using stored plasma, were performed. The patient did not respond and thrombocytopenia persisted.

On day 13 , there was a sudden and dramatic deterioration in neurological status with coma and a right hemiparesis. Computed tomographic investigation of the brain was reported as normal. The patient also developed progressive oliguric renal failure and was treated with peritoneal dialysis.
The patient died on day 21 having been unresponsive to plasma infusion, plasmapheresis, vincristine, corticosteroids, acetylsalicylic acid and dipyridamole. Post mortem examination demonstrated platelet thrombi in the small vessels of the heart, kidneys, pancreas, adrenals, parathyroid glands, pituitary, lymph nodes, uterus and ovaries. Gross and microscopic examination of the brain was normal.

\section{SPECIAL LABORATORY INVESTIGATIONS}

The multimeric pattern of the patient's von Willebrand factor (vWF) was studied using crossed immunoelectrophoresis. The total amount was increased slightly (1.9 iu/mL, with upper limit of normal range 1.6), and there was loss of large multimers of $v W F$ at the time of the acute thrombocytopenic episode (Figure 1).

To determine if there was a platelet aggregating factor present, the ability of the patient's plasma to induce the release of ${ }^{14} \mathrm{C}$-serotonin from ${ }^{14} \mathrm{C}$-serotonin-radiolabelled normal platelets was measured. Calcium-dependent cysteine protease (calpain) activity was confirmed by inhibition of this reaction by known inhibitors to calpain (leupeptin and iodoacetic acid). In addition, the ability of the calpain in the patient's serum to cleave the glycocalicin component of glycoprotein Ib from normal platelets was measured $(4,5)$.

The patient had calpain present in the plasma during the thrombocytopenic episode. Previous experiments have shown that calpain activity is not present in patients with other thrombocytopenic disorders including idiopathic thrombocytopenic purpura and disseminated intravascular coagulation. Via the same methods, calpain activity was not detectable in the supernatant from the $\mathrm{C}$ jejuni cultures.

\section{DISCUSSION}

Over the past several years major strides have been made in the improvement of our understanding of thrombotic thrombocytopenic purpura and hemolytic uremic syndrome. Although 
these disorders have considerable clinical similarities in that both are associated with thrombocytopenia and schistocytic hemolytic anemia, different organs are primarily affected: the brain is frequently affected in thrombotic thrombocytopenic purpura versus the kidneys in hemolytic uremic syndrome. Studies examining the pathogenesis of the two disorders have focused on the differences rather than the similarities of the disorders: hemolytic uremic syndrome is frequently preceded by an enteric infection and a number of recent reports have documented the high frequency of a verotoxin-producing $E$ coli in epidemic outbreaks of this disorder. C jejuni enteritis has also been implicated in the pathogenesis of hemolytic uremic syndrome (11-15). In contrast, thrombotic

ACKNOWLEDGEMENTS: This study was partially supported by a grant from the Heart and Stroke Foundation of Ontario.

\section{REFERENCES}

1. Brain N iC, Kelton JG. Thrombotic thrombocytopenic purpura and the hemolytic uremic syndrome. In: Brain $M$, McCulloch P, eds. Current Therapy in Hematology-Oncology. Philadelphia: BC Decker Inc 1983:193-6.

2. Aster RH. Thrombocytopenia due to enhanced platelet destruction. In: Williams WJ, Beutler E, Erslev AJ, Lichtman MA, eds. Hematology, 3rd edn. New York: McGraw Hill Book Company, 1983:1034-9.

3. Lian EC-Y, Harkness DR, Burnes JJ, Wallach H, Nunez R. The presence of platelet aggregating factor in the plasma of patients with thrombotic thrombocytopenic purpura and its inhibition by normal plasma. Blood 1979;53:333-8.

4. Kelton JG, Moore JC, Murphy WG. Studies investigating platelet aggregating and release initiated by sera from patients with thrombotic thrombo- thrombocytopenic purpura is not usually associated with a preceding infection (16). Recent research activity concerning thrombotic thrombocytopenic purpura has focused upon attempts to identify the platelet aggregating factor found in these patients' plasma. One group has reported a 37 kilodalton protein that can be neutralized by IgG $(6,7)$. Another group of investigators found evidence of unregulated calpain activity in the sera of these patients $(8-10)$. The current case report suggests the possibility of a link between an infecting enteric organism that frequently triggers hemolytic uremic syndrome and the development and presence of calpain activity in the plasma. However, a direct causal association could not be proven. Although it is likely that C jejuni triggered the thrombotic thrombocytopenic purpura episode in this patient, the organism by itself does not produce calpain, as tested using two different bioassays. Thus, although this study suggests a link between the infec. tion and the development of throm. botic thrombocytopenic purpura via release of calpain, it does not elucidate the linkage itself. It is possible that an infecting organism triggers a complex immunological response that in some way results in the generation of unregu. lated calpain in the plasma of patients with thrombotic thrombocytopenic purpura. The calpain activity, in turn, could cause platelet aggregation and the clinical syndrome of thrombotic thrombocytopenic purpura. Studies are currently underway to try and identify the link between infection and the generation of calpain. cytopenic purpura. Blood 1987;69:9248.

5. Murphy WG, Moore JC, Kelton JG. Calcium-dependent cysteine protease activity in the sera of patients with thrombotic thrombocytopenic purpura. Blood 1987;70:1683-7.

6. Siddiqui FA, Lian EC-Y. Novel platelet agglutinating protein from a thrombotic thrombocytopenic purpura plasma. J Clin Invest 1985;76:1330-7.

7. Lian EC-Y, Mui PT, Siddiqui FA, Chiu AY, Chiu LL. Inhibition of platelet-aggregating activity in thrombotic thrombocytopenic purpura plasma by normal adult immunoglobulin G. J Clin Invest 1984;73:548-55.

8. Murphy WG, Moore JC, Kelton JG. Calcium-dependent cysteine protease activity in the sera of patients with thrombotic thrombocytopenic purpura. Blood 1987;70:1683-7.

9. Kelton JG, Moore J, Santos A, Sheridan D. Detection of a plateletagglutinating factor in thrombotic thrombocytopenic purpura. Ann Intern Med 1984;101:589-93.

10. Murphy WG, Moore JC, Barr RD, Pai MKR, Kelton JG. Relationship between platelet aggregating factor and von Willebrand factor in thrombotic thrombocytopenic purpura.

Br J Haematol 1987;66:509-13.

11. Chamovitz BN, Hartstein AI,

Alexander SR, Terry AB, Short P,

Katon R. Campylobacter jejuni-associated hemolytic-uremic syndrome in a mother and daughter. Pediatrics 1983;71:253-6.

12. Denneberg T, Friedberg M, Holmberg L, et al. Combined plasmapheresis and hemodialysis treatment for severe hemolytic-uremic syndrome following campylobacter colitis. Acta Paediatr Scand 1982;71:243-5.

13. Schulman ST, Moel D. Campylobacter infection. Pediatrics 1983;72:437. (Lett)

14. Delans RJ, Biuso JD, Saba SR, Ramirez G. Hemolytic uremic syndrome after campylobacter-induced diarrhea in adult. Arch Intern Med 1984;144:1074-6.

15. Ashraful JH, Akbar MS. Hemolyticuremic syndrome and campylobacter Med J Aust 1985;142:662-3. (Lett)

16. Morton AR, Yu R, Waldek S, Holmes AM, Craig A, Mundy K. Campylobac. ter induced thrombotic thrombocytopenic purpura. Lancet 1985;ii:1133-4. (Lett) 


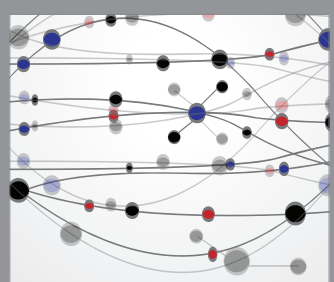

The Scientific World Journal
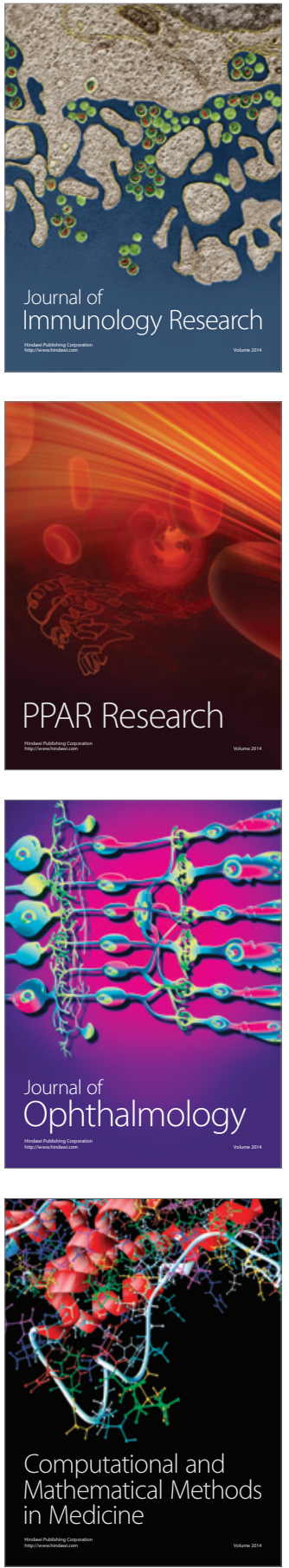

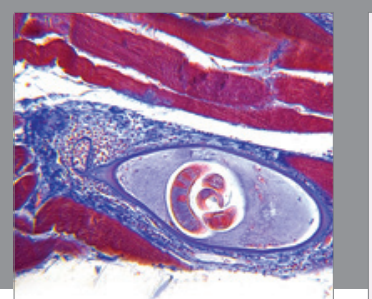

Gastroenterology Research and Practice

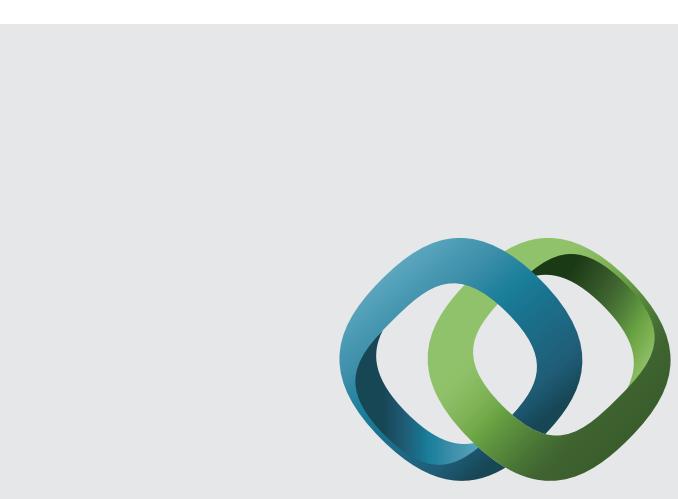

\section{Hindawi}

Submit your manuscripts at

http://www.hindawi.com
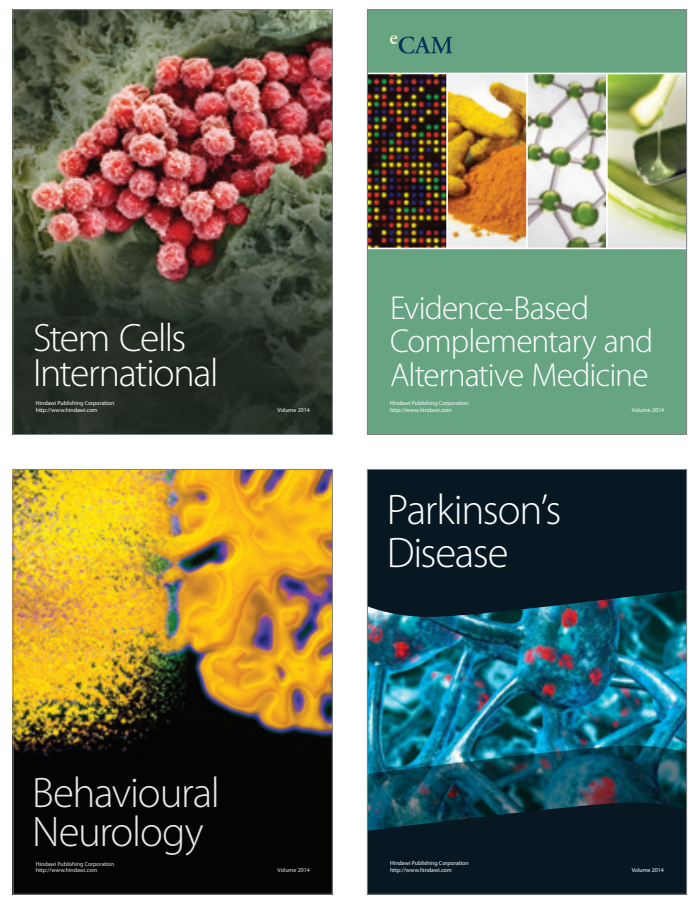
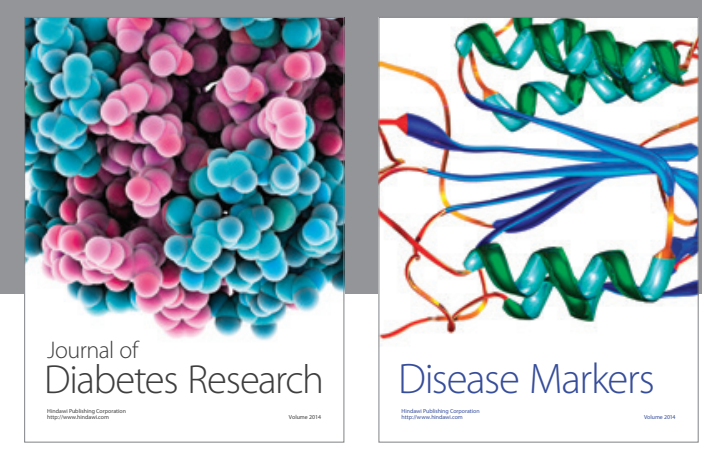

Disease Markers
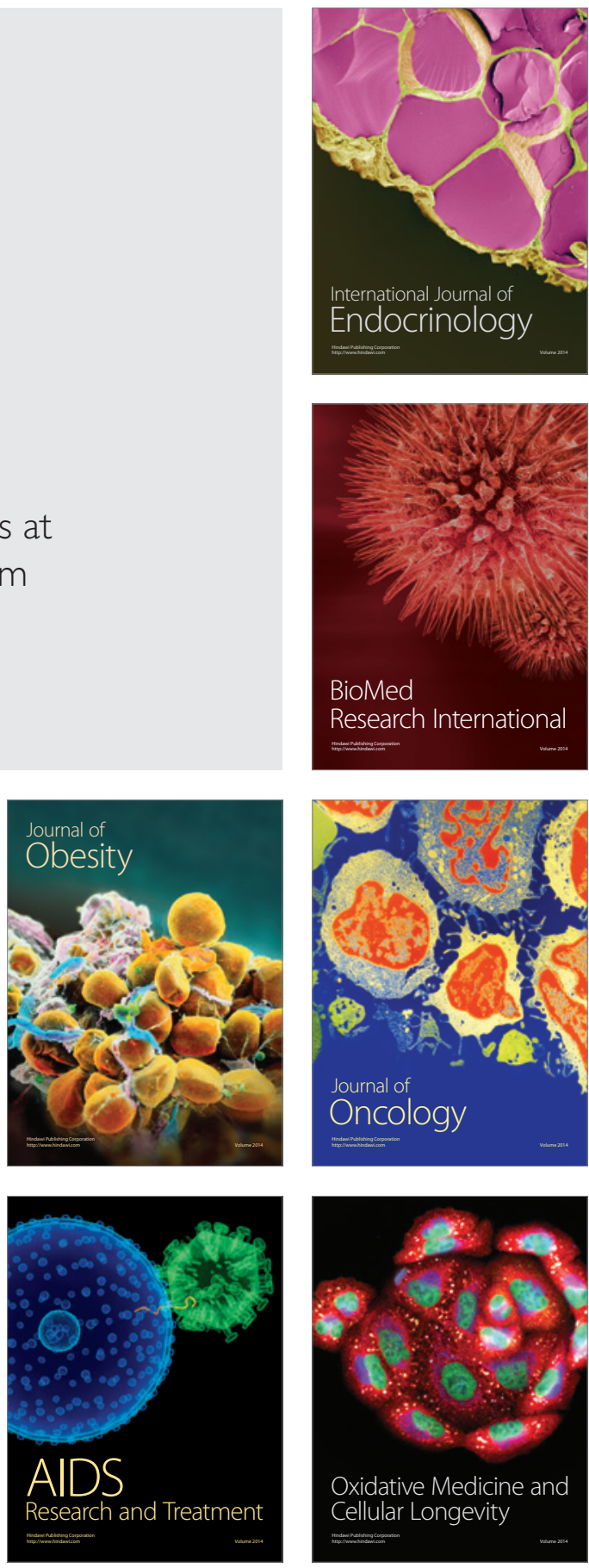